\title{
Analisis Preventive Maintenance pada Unit Haul Truck Tipe Cat 777e dengan Menggunakan Siklus Plan, Do, Check, Action (PDCA) di PT. Lawang Sampar Dodo
}

\author{
Iksan Adiasa*1, Yunan Fachri ${ }^{2}$, Ryan Suarantalla ${ }^{3}$, dan Ismi Mashabai ${ }^{4}$ \\ Teknik Industri, Fakultas Teknik, Universitas Teknologi Sumbawa \\ Jl. Raya Olat Maras, Kabupaten Sumbawa, Nusa Tenggara Barat. 84371, Indonesia \\ Email: iksan.adiasa@uts.ac.id ${ }^{1}$, yunanfachri450@gmail.com², ryan.suarantalla ${ }^{3}$,ismi.mashabai@uts.ac.id ${ }^{4}$
}

\begin{abstract}
Abstrak
Perawatan berkala adalah suatu kegiatan service yang dilakukan secara berkala dan sudah terjadwalkan dalam suatu kurun waktu yang relatif cukup lama atau setelah melewati beberapa kali melakukan service rutin. Hasil dari Perawatan berkala ini digunakan untuk meningkatkan performa kerja dari suatu unit mesin produksi untuk memudahkan pemakaian, menunjang keamanan dan kenyamanan dari suatu pekerjaan. PT Lawang Sampar Dodo merupakan spesialisasi dalam penyediaan, manajemen dan pengembangan tenaga kerja untuk sektor pertambangan, manufaktur, teknik, konstruksi dan infrastruktur. Kegiatan penelitian ini bertujuan untuk mengetahui preventive maintenance pada unit Haul truck tipe CAT 777E sekaligus menganalisa permasalahan preventive maintenance pada unit Haul truck tipe CAT 777E. Analisa dilakukan dengan menggunakan siklus Plan, Do, Check, action (PDCA). Hasil dan kesimpulan yang diperoleh adalah unit hull truck tipe CAT 777E adalah salah satu jenis haul truck yang rutin dilakukan preventive maintenance dan permasalahan pada preventive maintenance haull truck tipe CAT 777E salah satunya terjadi karena operator kurang mendapatkan training dari departemen OTD yang mengakibatkan operator jarang melakukan Pelaksanaan Perawatan Harian (P2H).
\end{abstract}

Kata kunci: Perawatan Berkala, Preventive Maintenance, Plan Do Check Action (PDCA)

\section{Abstract}

Periodic maintenance is a service activity that is carried out periodically and has been scheduled in a relatively long period of time or after several times through routine service. The results of this periodic maintenance are used to improve the work performance from a unit of production machine to easy of use, support the safety and comfort for a job. PT Lawang Sampar Dodo specializes in the supply, management and development of the workforce for the mining, manufacturing, engineering, construction and infrastructure sectors. This research activity aims to determine preventive maintenance on the CAT 777E Haul truck unit type as well as to analyze about preventive maintenance problems on the CAT 777E Haul truck unit type. Analysis is carried out by using the Plan, Do, Check, action (PDCA) cycle. The results and conclusions obtained are the CAT 777E haul truck unit type is one of the types of haul trucks which is routinely carried out preventive maintenance, and the problems in preventive maintenance of CAT 777E haul truck unit type one of them happened because the operator lacks of training from the OTD department which results in the operator rarely doing Pelaksanaan Perawatan Harian $(\mathrm{P} 2 \mathrm{H})$.

Keywords: Periodic Maintenance, Preventive Maintenance, Plan Do Check Action (PDCA)

\section{Pendahuluan}

Selain faktor manusia, dalam dunia industri juga membutuhkan mesin atau peralatan untuk menunjang suksesnya sebuah sistem kerja. Adapun mesin atau peralatan tersebuat harus selalu pada performa maksimal agar menghasilkan produksi yang sesuai dengan kebutuhan konsumen. Untuk menjaga kondisi mesin agar tetap pada performa maksimal dibutuhkan pengecekan dan perawatan secara berkala agar mesin dapat bekerja sesuai target yang diinginkan.

Perawatan berkala adalah suatu kegiatan servis yang dilakukan secara berkala dan sudah ter-jadwal-kan dalam suatu kurun waktu yang relatif cukup lama atau setelah melewati beberapa kali melakukan service rutin (Ansori dan Mustajib, 2013). Hasil dari Perawatan berkala ini digunakan untuk meningkatkan performa kerja dari suatu unit mesin produksi untuk memudahkan pemakaian, menunjang keamanan dan kenyamanan dari suatu pekerjaan (Corder dan Hadi, 1988). Hasil dari Perawatan berkala ini juga kemudian dapat diaplikasikan pada sistem kerja yang melibatkan manusia saat melakukan interaksi dengan komponen sistem kerja tersebut baik secara langsung maupun tidak langsung,

\footnotetext{
${ }^{*}$ Penulis korespondensi
} 
sehingga 3 diperoleh suatu sistem kerja yang mendukung pekerja untuk beraktivitas secara lebih efektif dan efisien.

Preventive Maintenance sangat penting untuk mendukung fasilitas produksi yang termasuk dalam golongan "critical unit". Teknik perawatan ini dilakukan secara inspeksi terhadap asset peralatan untuk memprediksikan terhadap kerusakan/kegagalan yang akan terjadi. Preventive Maintenance adalah suatu pendekatan yang inovatif dalam maintenance dengan cara mengoptimasi keefektifan peralatan serta mengurangi/menghilangkan kerusakan mendadak (breakdown) dengan melakukan identifikasi terlebih dahulu (Limantoro, 2013).

Menurut Dhillon (2002), preventive maintenance merupakan semua tindakan yang dilakukan dalam sebuah jadwal yang terencana, periodik, dan spesifik untuk menjaga sebuah perangkat dalam kondisi operasional yang ditentukan, dengan melalui proses pemeriksaan dan rekondisi.

Preventive Maintenance adalah kegiatan pemeliharaan dan perawatan yang dilakukan untuk mencegah timbulnya kerusakan- kerusakan yang tidak terduga dan menemukan kondisi atau keadaan yang dapat menyebabkan fasilitas produksi mengalami kerusakan pada waktu proses produksi (Haslindah dkk., 2017). Jadi, semua fasilitas produksi yang mendapatkan perawatan (Preventive Maintenance) akan terjamin kontinuitas kerjanya dan selalu diusahakan dalam kondisi atau keadaan yang siap dipergunakan untuk setiap operasi atau proses produksi pada setiap saat.

Menurut Heizer dan Render (2005), Metode Plan, Do, Check, Action (PDCA) merupakan model dalam melakukan perbaikan terus - menerus dengan rencanakan, lakukan, periksa, dan tindakan. Siklus PDCA umumnya digunakan untuk mengetes dan mengimplementasikan perubahan-perubahan untuk memperbaiki kinerja produk, proses atau suatu sistem di masa yang akan datang. Dari hasil penilaian tersebut dilakukan analisis untuk merencanakan pengembangan berikutnya. Demikian seterusnya sehingga siklus PDCA berjalan dan organisasi akan selalu mampu memenuhi standar mutu dan berkembang secara berkelanjutan.

PT Lawang Sampar Dodo merupakan spesialisasi dalam penyediaan, manajemen dan pengembangan tenaga kerja untuk sektor pertambangan, manufaktur, teknik, konstruksi dan infrastruktur. PT Lawang Sampar Dodo memiliki pengalaman dalam menyediakan dan mengelola tenaga kerja lengkap atau kelompok kerja terpilih untuk memenuhi persyaratan kerja jangka pendek dan jangka panjang dari klien Indonesia pada proyek di seluruh Indonesia. Melalui penelitian ini, diharapkan dapat mengetahui Preventive Maintenance pada unit Haul truck tipe CAT 777E sekaligus menganalisa permasalahan Preventive Maintenance pada unit Haul truck tipe CAT 777E.

\section{Metode Penelitian}

Pada penelitian ini, data yang diperlukan adalah data periodic preventive maintenance pada unit Haul truck tipe CAT 777E. Selanjutnya data ini dapat digunakan untuk mengetahui part atau komponen apa saja yang akan diperbaiki atau diganti saat proses preventive maintenance. Data yang digunakan terdiri dari data primer dan data sekunder. Data primer penelitian ini didapat dari pengamatan, interview serta dokumentasi langsung terhadap hasil preventive maintenance pada unit haul truck tipe CAT 777E. Adapun data sekunder yang digunakan dalam penelitian ini adalah dokumen Servive Information System (SIS) dan manual book operation dari unit haul truck CAT 777E.

Kemudian untuk menyelesaikan permasalahan tersebut, maka perlu dilakukan penyelesaian sebegai berikut:

1. Stratifikasi

Mengklasifikasikan persoalan menjadi kelompok sejenis yang lebih kecil. Dari data Service Information System (SIS), dapat diklasifikasikan berdasarkan jenis Pekerjaan perawatan yang dilakukan, yaitu: pergantian (replace), perbaikan (repair), bongkar \& pasang (assembly \& disassembly), pemastian (obtain), amati (inspect), pemastian/percobaan (ground test).

2. Diagram Sebab Akibat (Fishbone)

Diagram sebab akibat bertujuan untuk menunjukan faktor-faktor penyebab (Sebab) dan karakteristik kualitas (Akibat). Diagram sebab akibat ini menunjukan lima faktor yang menjadi sebab suatu akibat. Kelima faktor tersebut adalah manusia, mesin, material, metode dan uang.

3. Plan Do Check Action

Diagram sebab akibat bertujuan untuk menunjukan faktor-faktor penyebab untuk kemudian didapatkan permasalahan yang terjadi serta dapat dirumuskan solusi-solusi serta pemecahan dari masalah yang ada.

\section{Hasil dan Pembahasan}

Berdasarkan hasil pengamatan yang diperoleh peneliti di PT Lawang Sampar Dodo selama satu bulan, yaitu pada bulan Agustus 2019. Terdapat satu unit Haul truck tipe CAT 777E yang dilakukan preventive maintenance every 500 Service Hours (perawatan berkala 500 jam) yaitu unit Haul truck CAT 777E unit number RDT 178.

a. Preventive Maintenance setiap $500 \mathrm{Jam}$

Perawatan berkala 500 jam adalah perawatan yang dilakukan ketika unit beroperasi selama 500 jam dengan berpatokan kepada service hours meter untuk menentukan kapan pemeliharaan harus dilakukan. Ada beberapa jenis pekerjaan yang dilakukan saat perbaikan berkala 500 jam, yaitu: 
1. Inspeksi (Inspection)

Kegiatan inspeksi meliputi kegiatan pengecekan atau pemeriksaan secara berkala dimana maksud kegiatan ini adalah untuk mengetahui apakah perusahaan selalu mempunyai peralatan atau fasilitas produksi yang baik untuk menjamin kelancaran proses produksi. Sehingga jika terjadinya kerusakan, maka segera diadakan perbaikan-perbaikan yang diperlukan sesuai dengan laporan hasil inspeksi, dan berusaha untuk mencegah sebab-sebab timbulnya kerusakan dengan melihat sebab-sebab kerusakan yang diperoleh dari hasil inspeksi. Beberapa komponen yang diperiksa disaat PM 500 jam pada unit haul truck tipe CAT 777E yaitu oil filter, suction screen, engine air filter service indicator, engine valve rotator, differential and final drive, dan lain-lain.

2. Pengecekan (Check)

Pengumpulan dan pengevaluasian bukti mengenai informasi untuk menentukan dan melaporkan tingkat kesesuaian antara informasi dengan kriteria yang telah ditetapkan. Pemeriksaan juga harus dilaksanakan oleh orang yang kompeten dan independen. Beberapan komponen yang di check disaat PM 500 jam pada unit haul truck tipe CAT 777E yaitu cooling system coolant level, engine oil level, steering system oil level, magnetic plug, front wheel oil level, dan lain- lain.

3. Pergantian (Replace)

Adalah kegiatan mengganti komponen lama yang sudah tidak layak pakai dengan komponen baru agar performa unit kembali maksimal. Beberapan komponen yang dicek disaat PM 500 jam pada unit haul truck tipe CAT 777E yaitu oil filter, air filter, fuel filter, breather, dan lain-lain.

4. Pelumasan (Lubricate)

Sistem yang berfungsi untuk melumasi komponen-komponen engine yang memerlukan pelumasan dan menyediakan oli bersih pada lokasi yang tepat di engine, agar oli yang digunakan harus dapat bertahan pada suhu yang tinggi dan waktu penggantian oli yang lebih panjang serta pemakaian oli yang lebih rendah. Beberapan komponen yang di check disaat PM 500 jam pada unit haul truck tipe CAT 777E yaitu front suspension cylinder, steering cylinder bearing, steering tie road and pin bearings, dan lain-lain.

5. Percobaan (Ground test)

Yaitu kegiatan percobaan yang dilakukan oleh mekanik yang memiliki lisensi mengendarai unit untuk memastikan unit tersebut ready to use sebelum unit dikembalikan ke bagian produksi.
Selama bulan Agustus 2019, terdapat satu unit Haul truck tipe CAT 777E yaitu Haul truck unit number RDT 178 yang dilakukan pekerjaan preventive maintenance pada PT Lawang Sampar Dodo. Dimana pekerjaan yang dilakukan adalah perawatan berkala 500 jam. Beberapa jenis pekerjaan yang dilakukan dalam perawatan berkala 500 jam ini disajikan pada gambar 1, 2 dan 3 .

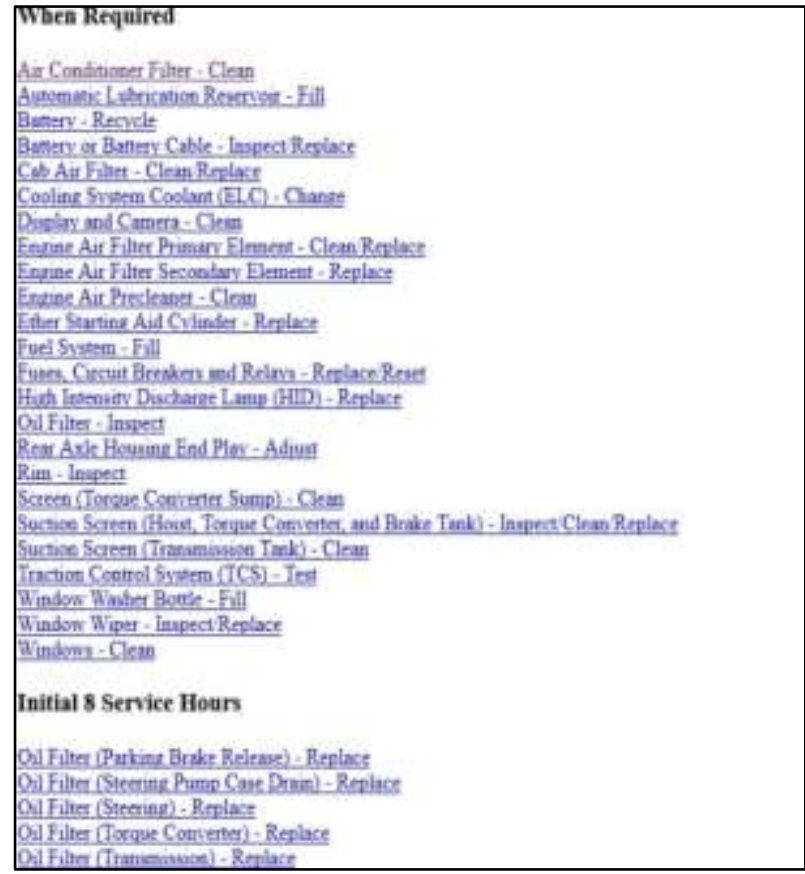

Gambar 1. Jenis Pekerjaan Perawatan Pada Haul truck Cat 777e bagian 1. (Sumber: Service Information System, PT. Trakindo Utama, 2019)

Dari jenis pekerjaan yang dilakukan dalam proses Preventive Maintenance (PM) 500 hours, dapat disimpulkan jenis-jenis pekerjaan yang dilakukan berdasarkan engine system sebagaimana disajikan pada tabel 1 . 


\begin{tabular}{|c|}
\hline $\begin{array}{l}\text { Every } 10 \text { Service Hours or Daily } \\
\text { Air Tank Moisture and Sediment - Drain } \\
\text { Backup Alarm - Test } \\
\text { Brakes, Indicators and Gauges - Test } \\
\text { Braking Svstem - Test } \\
\text { Cooling System Coolant Level - Check } \\
\text { Engine Air Filter Service Indicator - Inspect } \\
\text { Engine Oil Level - Check } \\
\text { Fuel Svstem Primary Filter (Water Separator) - Drain } \\
\text { Fuel Tank Water and Sediment - Drain } \\
\text { Hoist, Torque Converter and Brake Tank Oil Level - Check } \\
\text { Seat Belt - Inspect } \\
\text { Secondary Steering - Test } \\
\text { Steering System Oil Level - Check } \\
\text { Tire Inflation - Check } \\
\text { Transmission Tank Oil Level - Check } \\
\text { Every } 50 \text { Service Hours or Weekly } \\
\text { Body Pivot Bearings - Lubricate } \\
\text { Front Suspension Cylinder - Lubricate } \\
\text { Hoist Cylinder Bearings - Lubricate } \\
\text { Magnetic Plug (Differential) - Check } \\
\text { Magnetic Plug (Wheels) - Check } \\
\text { Rear Axle A-Frame Bearing - Lubricate } \\
\text { Rear Axle Housing Lateral Control Rod Bearings - Lubricate } \\
\text { Rear Suspension Cvlinder Bearings - Lubricate } \\
\text { Steering Cylinder Bearings - Lubricate } \\
\text { Steering Tie Rod and Pin Bearings - Lubricate } \\
\text { Enitial } 500 \text { Service Hours } \\
\text { Engine Valve Rotators - Inspect } \\
\end{array}$ \\
\hline
\end{tabular}

Gambar 2. Jenis Pekerjaan Perawatan Pada Haul truck Cat 777e bagian 2. . (Sumber: Service Information System, PT. Trakindo Utama, 2019)

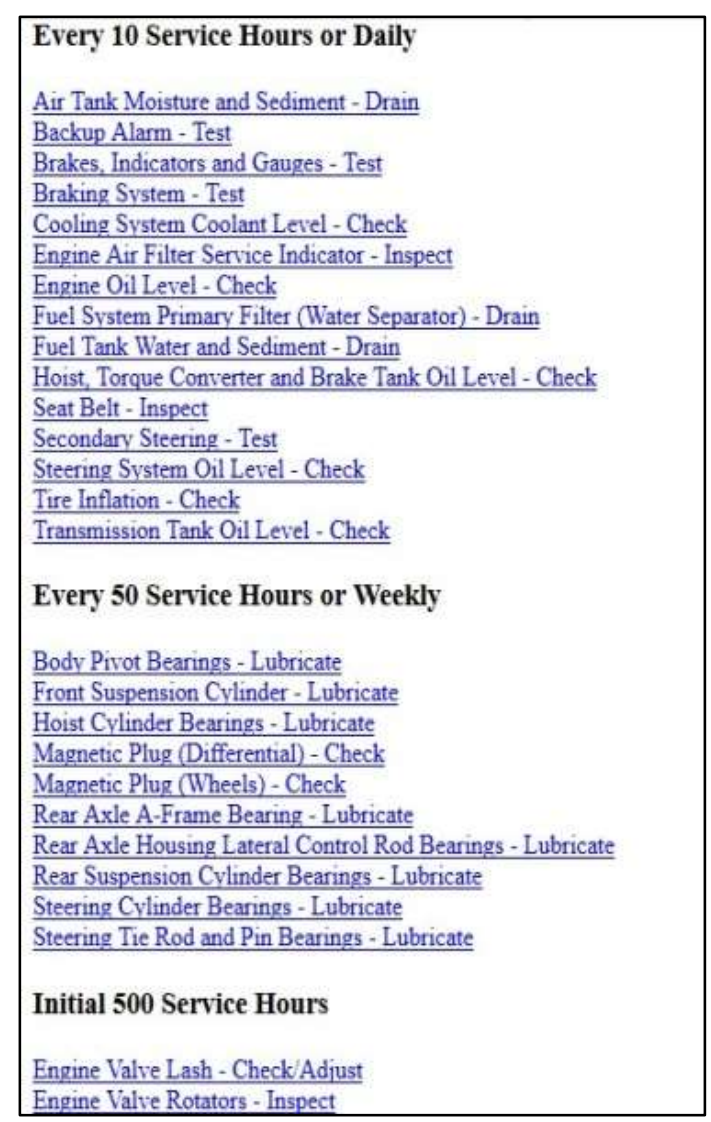

Gambar 3. Jenis Pekerjaan Perawatan Pada Haul truck Cat 777e bagian 3. (Sumber: Service Information System, PT. Trakindo Utama, 2019)
Tabel 1. Job Spesification PM 500 Hours

\begin{tabular}{|c|c|c|c|c|}
\hline \multirow{4}{*}{ NO } & \multicolumn{4}{|c|}{ JENIS ENGINE SISTEM } \\
\hline & $\begin{array}{l}\text { SISTEM } \\
\text { PENDIN } \\
\text { GIN }\end{array}$ & $\begin{array}{l}\text { SISTEM } \\
\text { PEMBAKA } \\
\text { RAN }\end{array}$ & $\begin{array}{l}\text { SISTEM } \\
\text { PELUMA } \\
\text { SAN }\end{array}$ & $\begin{array}{l}\text { SISTEM } \\
\text { PEMASUK } \\
\text { AN \& } \\
\text { PENGELU } \\
\text { ARAN } \\
\text { UDARA }\end{array}$ \\
\hline & \multicolumn{4}{|c|}{ ESTIMASI WAKTU PENGERJAAN PER SISTEM } \\
\hline & 30 Menit & 45 Menit & 90 Menit & 25 Menit \\
\hline 1 & $\begin{array}{l}\text { Cooling } \\
\text { System } \\
\text { Coolant } \\
\text { (ELC) - } \\
\text { Change }\end{array}$ & $\begin{array}{l}\text { Fuel System } \\
\text { - Fill }\end{array}$ & $\begin{array}{l}\text { Automatic } \\
\text { Lubrication } \\
\text { Reservoir - } \\
\text { Fill }\end{array}$ & $\begin{array}{l}\text { Engine Air } \\
\text { Filter Primary } \\
\text { Element - } \\
\text { Clean/Replac } \\
e\end{array}$ \\
\hline 2 & $\begin{array}{l}\text { Cooling } \\
\text { System } \\
\text { Coolant } \\
\text { Level - } \\
\text { Check }\end{array}$ & $\begin{array}{l}\text { Fuel System } \\
\text { Primary } \\
\text { Filter } \\
\text { (Water } \\
\text { Separator) - } \\
\text { Drain } \\
\end{array}$ & $\begin{array}{l}\text { Oil Filter } \\
\text { (Parking } \\
\text { Brake } \\
\text { Release) - } \\
\text { Replace }\end{array}$ & $\begin{array}{l}\text { Engine Air } \\
\text { Filter } \\
\text { Secondary } \\
\text { Element - } \\
\text { Replace }\end{array}$ \\
\hline 3 & $\begin{array}{l}\text { Cooling } \\
\text { System } \\
\text { Coolant } \\
\text { Sample } \\
\text { (Level 1) } \\
\text { - Obtain } \\
\end{array}$ & $\begin{array}{l}\text { Fuel Tank } \\
\text { Water and } \\
\text { Sediment - } \\
\text { Drain }\end{array}$ & $\begin{array}{l}\text { Oil Filter } \\
\text { (Steering) - } \\
\text { Replace }\end{array}$ & $\begin{array}{l}\text { Engine Air } \\
\text { Precleaner- } \\
\text { Clean }\end{array}$ \\
\hline 4 & $\begin{array}{l}\text { Cooling } \\
\text { System } \\
\text { Coolant } \\
\text { Sample } \\
\text { (Level 2) } \\
\text { - Obtain } \\
\end{array}$ & $\begin{array}{l}\text { Breather } \\
\text { (Fuel Tank) } \\
\text { - Replace }\end{array}$ & $\begin{array}{l}\text { Oil Filter } \\
\text { (Transmissi } \\
\text { on) - } \\
\text { Replace }\end{array}$ & $\begin{array}{l}\text { Engine Air } \\
\text { Filter Service } \\
\text { Indicator - } \\
\text { Inspect }\end{array}$ \\
\hline 5 & & $\begin{array}{l}\text { Fuel } \\
\text { System } \\
\text { Primary } \\
\text { Filter } \\
\text { (Water } \\
\text { Separator) } \\
\text { - Replace } \\
\end{array}$ & $\begin{array}{l}\text { Engine Oil } \\
\text { Level - } \\
\text { Check }\end{array}$ & $\begin{array}{l}\text { Air/Hydraulic } \\
\text { Cylinder } \\
\text { Breather - } \\
\text { Clean }\end{array}$ \\
\hline 6 & & $\begin{array}{l}\text { Fuel } \\
\text { System } \\
\text { Secondary } \\
\text { Filter - } \\
\text { Replace }\end{array}$ & $\begin{array}{l}\text { Different } \\
\text { ial and } \\
\text { Final } \\
\text { Drive } \\
\text { Oil } \\
\text { Sample - } \\
\text { Obtain }\end{array}$ & \\
\hline 7 & & $\begin{array}{l}\text { Fuel Tank } \\
\text { Cap and } \\
\text { Strainer- } \\
\text { Clean }\end{array}$ & $\begin{array}{l}\text { Engine Oil } \\
\text { Sample - } \\
\text { Obtain }\end{array}$ & \\
\hline 8 & & & $\begin{array}{l}\text { Transmissi } \\
\text { on Oil } \\
\text { Sample - } \\
\text { Obtain }\end{array}$ & \\
\hline 9 & & & $\begin{array}{l}\text { Engine Oil } \\
\text { and Filter - } \\
\text { Change }\end{array}$ & \\
\hline 10 & & & $\begin{array}{l}\text { Oil Filter } \\
\text { (Transmi } \\
\text { ssion) - } \\
\text { Replace }\end{array}$ & \\
\hline 11 & & & $\begin{array}{l}\text { Front } \\
\text { Wheel Oil - } \\
\text { Inspect }\end{array}$ & \\
\hline
\end{tabular}

Sumber: Service Information System, PT. Trakindo Utama (2019)

Dari data yang telah didapat, dapat diketahui bahwa pada komponen tiap sistema, yang paling banyak memakan waktu untuk dilakukan Preventive Maintenance yaitu pada lubrication system. Dari data tersebut, jumlah komponen lubrication system yang 
dilakukan Preventive Maintenance yaitu sebanyak 11 komponen dengan estimasi waktu pengerjaan yaitu selama 90 menit yang dapat dilihat pada tabel 1. Pekerjaan sebanyak dan selama ini dilakukan oleh satu orang mekanik yang melakukan perbaikan terhadap 11 komponen lubrication system. Padahal berdasarkan hasil wawancara dengan atasan dari operator tersebut, waktu dari kegiatan lubricant system seharusnya hanya sekitar 70 menit. Selanjutnya dilakukan interview atau wawancara terkait untuk mencari akar masalah dari lamanya kegiatan dari lubricant system yang mencapai 90 menit tersebut menggunakan Diagram Sebab Akibat atau Fishbone Diagram.

\section{b. Diagram Fishbone (Diagram Tulang Ikan)}

Diagram Sebab Akibat digunakan untuk mencari sebab-sebab terjadinya masalah berdasarkan faktor yang ada. Langkah awal dalam penyusunan Diagram sebab akibat adalah dengan melakukan brainstorming dengan Manager Bagian perawatan PT Lawang Sampar Dodo dilakukan menggunakan wawancara dengan pertanyaan 5 why untuk mencari akar masalah. Dari wawancara tersebut, didapatkan diagram sebab akibat dengan faktor paling besar yang menyebabkan kerusakan pada komponen lubrication system adalah faktor manusia. Manusia dalam hal ini adalah operator yang berfungsi mengoperasikan unit tanpa terlebih dahulu melakukan pelaksanaan perawatan harian $(\mathrm{P} 2 \mathrm{H})$.

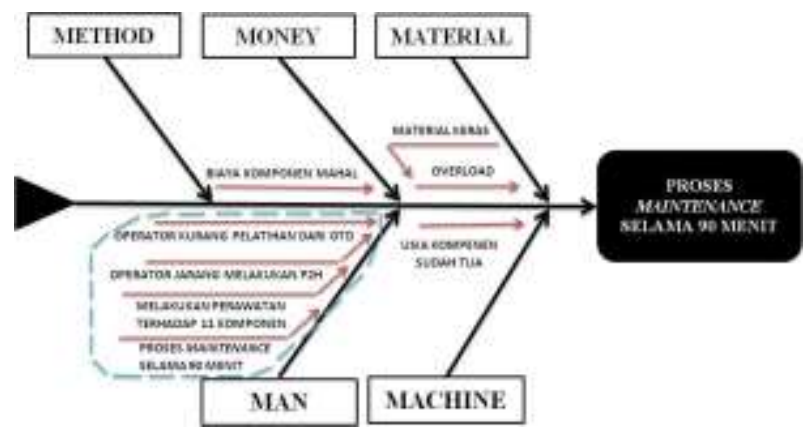

Gambar 4. Diagram Fishbone

\section{c. PDCA Permasalahan Preventive Maintenance}

Dari diagram Fishbone diatas, dapat diketahui bahwa masalah utama pada pekerjaan Preventive Maintenance adalah kurang perhatiannya operator terhadap unit yang dioperasikan. Hal ini berdampak pada faktor lingkungan dan produksi dalam permasalahan perusahaan. Untuk itu penulis mengusulkan suatu metode untuk mengurangi permasalahan tersebut, yaitu dengan menggunakan metode PDCA pada tabel 2.
Tabel 2. PDCA

\begin{tabular}{|c|c|}
\hline \multicolumn{2}{|c|}{ PLAN } \\
\hline 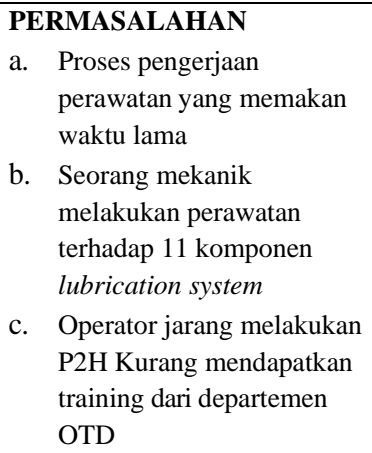 & $\begin{array}{l}\text { TARGET PERBAIKAN } \\
\text { a. Memberikan training kepada } \\
\text { operator } \\
\text { b. Rutin melaksanakan } \mathrm{P} 2 \mathrm{H}\end{array}$ \\
\hline $\begin{array}{l}\text { PENYEBAB } \\
\text { PERMASALAHAN } \\
\text { a. Jalan hauling yang tidak } \\
\text { standar } \\
\text { b. Operator tidak } \\
\text { mengoperasikan unit } \\
\text { sesuai SOP } \\
\text { c. Kurang perawatan pada } \\
\text { mesin dari operator } \\
\text { Akar masalah : } \\
\text { Usia mesin yang sudah tua }\end{array}$ & $\begin{array}{l}\text { SOLUSI PERMASALAHAN } \\
\text { Jangka pendek: } \\
\text { a. Lakukan training kepada } \\
\text { operator } \\
\text { b. Memberikan pengawasan } \\
\text { kepada unit secara intens } \\
\text { c. Tiap minggu harus } \\
\text { dilakukan preventive } \\
\text { maintenance } \\
\text { Jangka panjang: } \\
\text { a. Melakukan overhaul }\end{array}$ \\
\hline \multicolumn{2}{|r|}{ DO } \\
\hline \multicolumn{2}{|c|}{$\begin{array}{l}\text { IMPLEMENTASI : } \\
\text { a. Mengimplementasikan solusi jangka pendek dengan Bagian } \\
\text { Produksi dan membuat jadwal serta form pelaksanaan } \\
\text { perawatan mingguan. } \\
\text { b. Membahas solusi jangka Panjang dengan Bagian produksi dan } \\
\text { Divisi Keuangan untuk membahas kemungkinan pembiayaan. }\end{array}$} \\
\hline \multicolumn{2}{|c|}{ CHECK } \\
\hline \multicolumn{2}{|c|}{$\begin{array}{l}\text { PENGECEKAN : } \\
\text { Mesin dilakukan pengecekan setiap minggu bekerjasama dengan } \\
\text { Bagian Produksi dan hasil dilaporkan pada Kepala Bagian } \\
\text { Perawatan. }\end{array}$} \\
\hline \multicolumn{2}{|c|}{ ACTION } \\
\hline $\begin{array}{l}\text { TINDAK LANJUT } \\
\text { a. Bagian produksi dan Bagian } \\
\text { melakukan perawatan unit se } \\
\text { mencapai performa stanc } \\
\text { perbaikan tanpa menunggu } \mathrm{j} \\
\text { b. Jika mesin tidak memungk } \\
\text { maka disarankan untuk dil } \\
\text { yang baru }\end{array}$ & $\begin{array}{l}\text { erawatan harus konsisten dalam } \\
\text { ara rutin. Jika unit dirasakan tidak } \\
\text { r, untuk langsung dilakukan } \\
\text { lwal maintenance } \\
\text { kan untuk digunakan kembali, } \\
\text { xukan pergantian mesin dengan }\end{array}$ \\
\hline
\end{tabular}

\section{Kesimpulan}

Berdasarkan data yang telah dianalisis beserta hasil penelitian yang telah diuraikan pada maka dapat ditarik kesimpulan yaitu unit hull truck tipe CAT 777E adalah salah satu jenis haul truck yang rutin dilakukan Preventive Maintenance setiap 500 jam. Perawatan berkala 500 jam adalah perawatan yang dilakukan ketika unit telah beroperasi selama 500 jam kerja dengan berpatokan kepada service hours meter untuk menentukan kapan pemeliharaan harus dilakukan. Jenisjenis pekerjaan yang dilakukan saat Preventive 
Maintenance yaitu inspeksi keseluruhan unit, pengecekan terhadap komponen-komponen unit, pergantian terhadap komponen-komponen yang rusak, melakukan pelumasan terhadap komponen-komponen yang membutuhkan pelumasan dan teakhir yaitu percobaan (Ground Test) setelah seluruh rangkaian pekerjaan telah dilaksanakan.

Melalui analisis PDCA permasalahan pada preventive maintenance hull truck tipe CAT 777E terjadi karena operator kurang mendapatkan training dari departemen OTD yang mengakibatkan operator jarang melakukan Pelaksanaan Perawatan Harian $(\mathrm{P} 2 \mathrm{H})$ sehingga komponen terutama komponen pada sistem pelumasan (Lubrication System) mengalami banyak kerusakan yang diharuskan dilakukan perawatan terhadap komponen yang rusak tersebut. Selain itu faktor usia mesin yang sudah tua menjadi salah satu akibat kenapa unit sering dilakukan Preventive Maintenance sehingga perlu dilakukan usulan solusi jangka pendek agar sering melakukan training kepada operator, memberikan pengawasan kepada unit secara intens, tiap minggu harus dilakukan Preventive Maintenance. Sedangkan solusi jangka panjangnya yaitu melakukan overhaul terhadap unit Haul truck CAT 777E tersebut.

\section{Daftar Pustaka}

Ansori, N., \& Mustajib, M. I. (2013). Sistem Perawatan Terpadu. Graha Ilmu, Yogyakarta.

Corder, A., \& Hadi, K. (1988). Teknik Manajemen Pemeliharaan. Erlangga.

Dhillon, B. S. (2002). Engineering Maintenance "A Modern Approach". New York: CRC Process LLC.

Haslindah, A., Fadhli, F., Adrianto, A., \& Mansyur, R. (2017). Pengaruh implementasi warehouse management system terhadap inventory control finish good berbasis barcode pt. Dharana inti boga. ILTEK: Jurnal Teknologi, 12(02), 17601763.

Heizer, J., \& Render, B. (2005). Operations Management Edisi 7 Bahasa Indonesia. Jakarta: Salemba, 4.

Limantoro, D. (2013). Total Productive Maintenance di PT. X. Jurnal Titra, 1(1), 13-20.

Oktaria, S. (2011). Perhitungan dan Analisa Nilai Overall Equipment Effectiveness (OEE) Pada Proses Awal Pengolahan Kelapa Sawit (Studi Kasus: PT. $\mathrm{X})$. Universitas Indonesia, Jakarta. 